\title{
A reforma da Administração Pública Central no Portugal democrático: do período pós-revolucionário à intervenção da troika
}

\author{
César Madureira \\ Universidade Lusíada \\ Direção-Geral de Administração e Emprego Público (DGAEP) \\ Instituto Universitário de Lisboa (ISCTE-IUL) \\ Lisboa, Portugal
}

\begin{abstract}
Ultrapassado o período-pós revolucionário, ao longo das últimas décadas, as tendências de reforma administrativa em Portugal acompanharam aquilo que se passava no resto da Europa. Independentemente das idiossincrasias e das incoerências observadas, ao longo dos últimos 20 anos, o processo reformista foi marcado pela introdução das privatizações, da empresarialização da lógica administrativa, das tentativas de desburocratização e transparência na relação entre a administração e os cidadãos, da convergência de regimes laborais e da restruturação da Administração Pública Central. A partir de 2011, na sequência da assinatura do Memorando de Entendimento entre o governo português e a troika, a reforma restringiu-se essencialmente à aplicação de medidas avulsas que visaram sobretudo a redução dos custos da despesa pública. Não existindo para já referências teóricas científicas analíticas sobre a matéria tratada, o artigo apresenta uma abordagem descritiva e exploratória.
\end{abstract}

Palavras-chave: reforma; administração pública central; troika; memorando.

Reforma de la Administración Pública General en el Portugal democrático: del período post-revolucionario hasta la intervención de la Troika

Superado el periodo post-revolucionario, en las últimas décadas, las tendencias de la reforma administrativa en Portugal han seguido lo que ocurría en el resto de Europa. Independientemente de la idiosincrasia y las inconsistencias observadas en los últimos 20 años, el proceso de reforma se ha caracterizado por la introducción de la privatización, la mercantilización de la lógica administrativa, los intentos de reducir la burocracia y de mejorar la transparencia en la relación entre gobierno y ciudadanos, la convergencia de los sistemas laborales y la reestructuración de la Administración General del

DOI: http://dx.doi.org/10.1590/0034-7612129503

Artigo recebido em 23 jan. 2014 e aceito em 4 dez. 2014.

(cc) BY-NC

Rev. Adm. Pública - Rio de Janeiro 49(3):547-562, maio/jun. 2015 
Estado. A partir de 2011, tras la firma del Memorando de Entendimiento entre el gobierno portugués y la troika, la reforma se limita principalmente a la aplicación de medidas individuales nada más que para reducir los costes de los gastos públicos. Por ahora, no hay referencias teóricas científicas analíticas para el material tratado. Por lo tanto, este trabajo presenta un enfoque descriptivo y exploratorio.

Palabras clave: reforma; administración general del Estado; troika; memorando.

Reform of Portugal's Central Government in the democratic period: from post-revolutionary stage to Troika's intervention

After the post-revolutionary period, over the past decades, the trends of administrative reform in Portugal followed what was happening in the rest of Europe. Regardless of the idiosyncrasies and inconsistencies observed over the last twenty years, the reform process was marked by the introduction of privatization, corporatization of administrative organization, attempts to reduce bureaucracy and transparency in the relationship between government and citizens, convergence of labor regimes and restructuration of the the Central Government Administration. From 2011, following the signing of the Memorandum of Understanding (MoU) between the Portuguese government and the troika, reform was restricted mainly to the implementation of individual measures that mainly targeted cost reduction of public expenditure. By now, there are no scientific theoretical analytical results for the subject matter. For this reason, the paper presents a descriptive and exploratory approach.

Keywords: reform; central government (or central public administration); troika; MoU.

\section{Introdução}

Ainda que continuando a carecer de uma definição consensual, o conceito de reforma administrativa pressupôs, em todas as formas que assumiu nos diferentes países ocidentais, aquilo que Lane (1995) designou por substituição do "Estado administrativo" pelo "Estado managerial". Também em Portugal, foi o managerialismo que se afirmou nos anos 1980-90 do século passado (Rocha, 2009; Rato, 2013a) como principal corrente crítica das ineficiências tradicionalmente conotadas com as organizações burocráticas. De um ponto de vista teórico, essa nova concepção de gestão apostava na descentralização, na flexibilização, na autonomia e no achatamento das hierarquias, princípios já defendidos por diversos autores no contexto da modernização empresarial do sector privado em seus diversos ramos de atividade (Wright, 1997).

No Portugal democrático, ao longo das últimas quatro décadas, a reforma na Administração Pública Central (APC) tem-se afirmado como um processo constante, marcando presença nas agendas dos sucessivos governos constitucionais (Madureira e Ferraz, 2010; Madureira, Asensio e Rodrigues, 2013). Com efeito, independentemente dos partidos políticos no poder, as propostas e as medidas de reforma marcaram desde o fim dos anos 1970 todos os programas de governo (Madureira, Asensio e Rodrigues, 2013). De acordo com Bilhim (2003), Rocha (2009) e Madureira e Ferraz (2010), as medidas de reforma iniciadas nos anos 1990, essencialmente centradas em privatizações, desburocratização e proximidade dos cida- 
dãos, diferem daquelas que foram promovidas a partir do início do século e que se centraram sobretudo em promover a eficiência, a eficácia e a qualidade dos serviços públicos.

Contudo, com a crise financeira internacional de 2008 e com a entrada da troika em Portugal, a partir de 2011, as diretivas constantes do Memorando de Entendimento (EC, IMF e ECB, 2011) e as opções políticas do XIX Governo Constitucional concorreram para que as medidas de reforma na administração pública portuguesa passassem a resultar predominantemente das exigências feitas pelo exterior.

Depois de fazer um enquadramento sobre o contexto em que se iniciaram as reformas no período pós-revolucionário, o artigo fará uma caracterização e uma discussão das principais linhas e medidas de reforma implementadas ao longo das quatro últimas décadas, assim como de suas causas e consequências.

\section{As reformas da administração pública em Portugal: do período pós- revolucionário aos anos 1990}

Não obstante o fato de o período pós-revolucionário não ter apresentado qualquer manifestação inequívoca de mudança estrutural e orgânica na administração pública portuguesa, a Oecd (1995) aponta a revolução de 1974 e a entrada de Portugal na Comunidade Europeia em 1986 como marcos essenciais na realização e na orientação da reforma administrativa. A competitividade passou a constituir-se como uma prioridade para as políticas públicas do país, pelo que se passou a requerer um desenvolvimento de novas capacidades e competências da economia em geral e da administração em particular. Dessa forma, impunha-se uma transformação de uma administração fechada, centralizada e introvertida para uma administração aberta, extrovertida, orientada para os cidadãos e potenciadora de uma sociedade democrática (Oecd, 1995; Madureira, 2004).

Para os políticos portugueses, no período entre 1976 e 1994, foi ficando progressivamente mais claro que a nova sociedade e a nova economia estavam dependentes do funcionamento da administração pública. Segundo a Oecd (1995), o movimento da reforma administrativa em Portugal apresentou-se como consensual no elencar de suas principais preocupações. Foram elas a melhoria da imagem do serviço público e a recuperação do seu prestígio, a dignificação dos funcionários públicos e o aumento das suas qualificações acadêmicas e profissionais, a mudança atitudinal dos dirigentes e funcionários, a aproximação da administração aos cidadãos (evidenciando a transparência), a quebra das cadeias de comando centralizadas/autocráticas com delegação e descentralização da autoridade, a simplificação de regras e procedimentos e a passagem de um ambiente de trabalho dominado pelas regras para uma gestão flexível e motivada para o alcance de resultados.

A reforma administrativa no terreno foi-se também constituindo como fonte de aprendizagem. Se numa primeira fase a estratégia foi montada numa abordagem global por meio de uma responsabilidade centralizada, cedo se constatou que uma tentativa de mudança em todas as frentes poderia falhar por se tornar demasiadamente pesada e ambiciosa (Côrte-Real, 
1999). Dessa forma, no início da década de 1990, a responsabilidade da reforma foi dada a um pequeno grupo flexível (Secretariado para a Modernização Administrativa — SMA) que por meio de uma Secretaria de Estado reportava diretamente ao primeiro-ministro. Essa unidade agiu como animadora, coordenadora e moderadora da(s) reforma(s) que ia(m) surgindo nos mais diversos setores e unidades operacionais, compelidos eles próprios a desenharem e a implementarem suas iniciativas de modernização. As intervenções para a modernização da administração pública passaram a ter preocupações de gestão (e não só preocupações de caráter puramente administrativo), fazendo do seu alvo a mudança de valores e de cultura em detrimento da simples modificação de procedimentos e de métodos, e seguindo uma via de abordagem radical seletiva (Côrte-Real, 1999; Madureira, 2004).

\section{Os anos 1990 e o início do século XXI}

De acordo com a Oecd (1995), a meio dos anos 1990 esta mesma organização elaborou uma lista de recomendações para a reforma administrativa em Portugal, entre as quais avultavam a necessidade de uma intervenção na cultura organizacional vigente visando essencialmente a mudança de comportamentos de funcionários e dirigentes, a necessidade da aproximação ao cidadão, a consideração da abordagem radical seletiva como elemento estratégico de reforma, a importância de tornar visíveis as medidas de reforma cujos beneficiários pudessem ser os cidadãos, a importância do envolvimento político nas reformas, a necessidade da participação de atores exteriores à administração no processo de reforma como essencial para uma identificação de vícios e deficiências mais livre e descomprometida e, por fim, a tentativa de mentalizar os dirigentes do seu papel de agentes ativos de mudança.

O estudo da Oecd (1995) não teve no entanto a capacidade de antecipar que, como tantos outros processos de mudança, também o português estaria marcado por sua incoerência, ${ }^{1}$ fazendo coexistir na prática simultaneamente três modelos distintos de administração com distintos objetivos e filosofias organizacionais: o modelo estatutário (até então o mais utilizado em Portugal, em que as práticas administrativas se encontravam altamente regulamentadas), o modelo político (fundado nos princípios da teoria da escolha pública) e o modelo managerial (decorrente da aplicação dos princípios do New Public Management). O resultado dessa sobreposição de filosofias foi a criação de um clima de contradições sucessivas, em que por um lado se clamava pelo outsorcing e pelo downsizing, propostos pelo New Public Management (NPM), e por outro se exortava a necessidade de participação dos funcionários na mudança. Contudo, na prática, os funcionários foram sendo confrontados com uma alternância de modelos de organização do trabalho e de gestão pública sem que fossem envolvidos na escolha ou na definição dos mesmos.

\footnotetext{
${ }^{1}$ A propósito da incoerência nos processos de reforma administrativa, ver Peters e Savoie (1996:281-290) e Giauque (2003:567-592).
} 
Independentemente das incoerências inventariadas, no que concerne à reforma administrativa em Portugal, pode afirmar-se que os anos 1990 foram marcados pela introdução de medidas que visavam as privatizações, mas sobretudo a desburocratização e a necessidade de uma maior proximidade e transparência na relação entre a administração e os cidadãos. Deuse então início a medidas que procuravam favorecer o acesso dos cidadãos à informação e aos serviços públicos num quadro de transparência e neutralidade da administração pública. Com efeito, os cidadãos estiveram no centro das preocupações das reformas (Araújo, 2005; Madureira e Ferraz, 2010) como o provam alguns dos resultados alcançados de que são exemplo:

— a criação da(s) Loja(s) do Cidadão (one stop citizen shop). Depois do surgimento em Lisboa da primeira loja, o conceito foi sendo difundido pelo país, o que contribuiu muito significativamente para o acesso dos cidadãos a diversos serviços públicos num único local físico.

- a criação de um novo quadro legal que veio alterar a relação vigente entre estado e cidadão. Com efeito, com o Código de Procedimento Administrativo (Lei no 442/91, de 15 de novembro) tornaram-se legalmente obrigatórios princípios como os da legalidade (art. 3ํㅡ), da

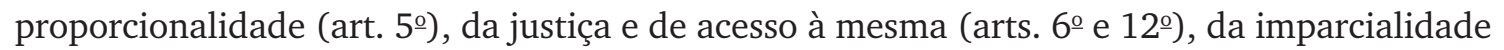
(art. 6ํ), da confiança e da lealdade (art. 6ํA), da colaboração entre a administração e os cidadãos (art. $7^{\circ}$ ), da participação (art. $8^{\circ}$ ), da desburocratização e da eficiência (art.10ำ).

Essas alterações legais acompanharam uma mudança de filosofia que deixava de encarar o cidadão comum apenas como um cumpridor de leis e de obrigações para passar a considerá-lo como um ser dotado de direitos, com poderes para requerer da administração serviços públicos que fossem prestados de forma eficiente, justa e transparente (Madureira e Ferraz, 2010).

No início dos anos 1990, de salientar ainda que o poder político passou a centralizar o poder administrativo na mão de políticos com o fim de evitar eventuais confrontos de opiniões ou discordâncias entre a alta esfera da função pública e o governo. Como lembra Rocha (1998), o Decreto-Lei no 323/89, de 26 de setembro, criou um estatuto especial para o pessoal dirigente, permitindo aos responsáveis políticos recrutar diretores e subdiretores gerais fora dos quadros da administração pública. Mesmo o recrutamento de diretores de serviços e de chefes de divisão passava a depender do poder político. Contudo, a partir de 1997, diluiu-se o confronto entre o poder político e os burocratas de carreira, nomeadamente através de uma despolitização dos quadros dirigentes da administração. Com efeito, a Lei no 13/97, de 23 de maio, restringia novamente a liberdade de escolha política aos diretores e subdiretores gerais, sendo os outros dirigentes recrutados por concurso público. Esse estado de coisas ver-se-ia novamente alterado em janeiro de 2004, altura em que voltou a preponderar a "confiança pessoal/política" para o provimento de titulares em cargos de direção intermédia. Com efeito, o no 3 do art. 21 da Lei no 2/2004, de 15 de janeiro, veio afirmar que os diretores das categorias intermédias (diretores de serviços e chefes de divisão) deveriam ser providos por despacho do dirigente do organismo, em comissão de serviço, e por um período máximo de três anos, renovável por igual período de tempo. Promulgada e publicada durante o ano civil de 2005, a Lei no $51 / 2005$, de 30 de agosto, voltou a promover a despolitização dos cargos de direção intermédia, estabelecendo que apenas os dirigentes de topo passassem a ser nomeados dire- 
tamente pelo governo. Em suma, no que concerne à politização dos níveis de direção, e em particular dos níveis de direção intermédia, as alterações ao longo das duas últimas décadas foram constantes e cíclicas.

No início do século XXI, as constantes pressões dos cidadãos, por um lado, e do contexto econômico, por outro, forçaram as administrações públicas por todo o mundo a concentrarem-se na questão da prestação dos serviços públicos com eficácia e eficiência às populações. Essas práticas encontravam como enquadramento teórico os princípios do New Public Management (Hood, 1991; Peters, 1996; Clarke e Newman, 2000; Rocha 2009), que desde os anos 1980 vinham alvitrando a aplicação dos dogmas da gestão privada ao setor público como solução para as ineficiências da burocracia. Nas reformas iniciadas no novo milênio, as práticas decorrentes da aplicação do NPM foram introduzidas de forma mais determinada do que havia ocorrido até então. Medidas como o contracting-out, as parcerias público-privadas, a gestão por objetivos, a avaliação de desempenho com critérios pretensamente mais objetivos e as novas regras estatutárias para os funcionários públicos contavam-se entre as principais novidades na gestão dos serviços públicos (Araújo, 2005; Rocha e Araújo, 2006; Madureira e Ferraz, 2010).

Entre as reformas efetuadas no início do século na administração pública portuguesa, de salientar a criação do Programa de Reestruturação da Administração Central do Estado (Prace), cujos principais objetivos se inscreviam numa perspetiva de reforma estruturante e transversal a toda a administração central. Era a primeira vez que um programa ousava encetar uma reforma tão abrangente. Na avaliação dos resultados da 1a fase do Prace, efetuada em 2006, concluía-se que, como previsto, por meio do programa tinha-se procedido a um decréscimo considerável do número de estruturas administrativas. Com efeito, considerando serviços centrais, órgãos consultivos, serviços desconcentrados, estruturas de missão e outras entidades, entre extinções, manutenções e criação de novas estruturas, a diminuição total foi de 187 organismos de um total de 518 (Madureira, Asensio e Rodrigues, 2013). Contudo, e embora o Relatório Final para a reestruturação da administração central, elaborado pela Comissão Técnica do Prace, conclua que os principais propósitos traçados foram atingidos, existiram resistências de diversa índole que contribuíram para o reconhecimento, em 2010, de que parte dos objetivos não tinha ainda sido alcançada (Madureira, Asensio e Rodrigues, 2013).

As principais reformas introduzidas em Portugal na primeira década do milênio (ver Quadro I) pressupunham a criação de uma cultura organizacional estranha àquela que tinha vigorado até então. A busca de eficiência, eficácia e responsabilização (accountability) nos serviços públicos procurava dar um contributo para a redução da despesa pública. Não obstante, a transição de um modelo burocrático para um modelo de gestão por objetivos nunca chegou a gerar consenso dentro da administração portuguesa. Dessa forma, nos dias de hoje, continuam por contabilizar os verdadeiros benefícios trazidos por uma gestão inspirada em técnicas até então exclusivas do setor privado. Bilhim (2003) refere mesmo que, sendo certo que essas técnicas podem produzir efeitos desejáveis no setor público, em si mesmas, nunca serão suficientes para melhorar a responsabilização e o comprometimento dos funcionários e dirigentes para com a coisa pública. 
Apesar de, ao longo das duas últimas décadas, as reformas na administração pública portuguesa terem tido por referência os princípios do NPM, que, de resto, assumiram um caráter de modismo em todo o mundo ocidental, a verdade é que aos poucos esse paradigma foi perdendo força (Pollitt e Bouckaert, 2000). Com efeito, princípios como os da orientação para o consenso, participação cidadã, transparência, equidade e inclusão, até ao início do século apresentados marginalmente e apenas constando como declarações de intenções para o futuro, passaram a partir de meados da primeira década do século XXI a assumir-se como o foco central da discussão sobre a modificação dos modelos de administração (Denhardt e Denhardt, 2003; Bovaird e Loffler, 2003; Nutley e Boaz, 2003; UN, 2008). Contudo, apesar do ensaio de aproximação ao cidadão posto em prática nos anos 1990, em Portugal as principais medidas de reforma que vingaram até ao presente respaldaram-se essencialmente nos princípios manageriais (Rocha, 2009; Madureira e Ferraz, 2010).

De salientar ainda que, independentemente das estratégias adotadas na administração pública portuguesa, ao longo do período histórico tratado, em momento algum se criou uma cultura de avaliação das medidas de reforma. Apesar de pontualmente se efetuarem pequenos ensaios de avaliação, como prova a já referida avaliação dos resultados da $1^{\text {a }}$ fase do Prace efetuada em 2006, em regra, o impacto e os resultados decorrentes da implementação da(s) reforma(s) administrativa(s) em Portugal não são conhecidos com suficiente grau de isenção e objetividade. A prova disso é o fato de não existirem praticamente referências bibliográficas a esse respeito. Esse constrangimento impossibilita-nos de fazer qualquer revisão de literatura global sobre a avaliação/resultados das medidas de reforma administrativa no Portugal democrático.

$$
\text { Quadro } 1
$$

\section{Principais reformas estruturais da administração pública central portuguesa ao longo da} primeira década do século XXI

\begin{tabular}{|c|c|}
\hline Reformas estruturais & Descrição das reformas \\
\hline $\begin{array}{l}\text { Reorganização do Estado } \\
\text { Lei no } 3 / 2004 \\
\text { Lei no } 4 / 2004\end{array}$ & Novo enquadramento legal para permitir a reorganização do Estado e da AP. \\
\hline $\begin{array}{l}\text { Programa de Restruturação da Administração } \\
\text { Pública Central (Prace) } \\
\text { Resolução do Conselho de Ministros nº } \\
\text { 39/2006 }\end{array}$ & $\begin{array}{l}\text { Objetivo de redução em 25\% do número de estruturas e de cargos dirigen- } \\
\text { tes na AP, assim como de criação de novos estatutos para } 430 \text { organismos. }\end{array}$ \\
\hline $\begin{array}{l}\text { Mobilidade especial } \\
\text { Lei no } 53 / 2006 \\
\text { Lei no } 64-A / 2008 \\
\text { Lei } n=12-A / 2008\end{array}$ & Promoção da mobilidade dos funcionários entre organismos públicos. \\
\hline $\begin{array}{l}\text { Vínculos, carreiras e Remunerações } \\
\text { Lei no } 12-A / 2008 \\
\text { Novo estatuto funcionários públicos } \\
\text { Lei no } 59 / 2008\end{array}$ & $\begin{array}{l}\text { O novo estatuto do funcionário apresenta um sistema de posições remunera- } \\
\text { tórias e um regime de emprego mais próximo do existente no setor privado. } \\
\text { Transformação de } 1715 \text { carreiras em } 3 \text { carreiras gerais. } \\
\text { Progressões e promoções baseadas na avaliação do desempenho. } \\
\text { Facilitação do "despedimento" se houver uma situação de extinção do posto } \\
\text { de trabalho. }\end{array}$ \\
\hline
\end{tabular}




\begin{tabular}{|c|c|}
\hline Reformas estruturais & Descrição das reformas \\
\hline $\begin{array}{l}\text { Avaliação de desempenho e gestão por ob- } \\
\text { jetivos } \\
\text { Lei no } 66-B / 2007\end{array}$ & $\begin{array}{l}\text { Definição de um sistema integrado de avaliação de desempenho para a admi- } \\
\text { nistração pública (Siadap) que avalia organizações, hierarquias e funcionários. }\end{array}$ \\
\hline $\begin{array}{l}\text { Novo estatuto disciplinar } \\
\text { Lei no } 58 / 2008\end{array}$ & Simplificação e maior celeridade nas punições por causas disciplinares. \\
\hline $\begin{array}{l}\text { Revisão dos benefícios sociais dos funcionários } \\
\text { públicos } \\
\text { Lei no } 4 / 2009\end{array}$ & $\begin{array}{l}\text { Convergência tendencial entre os sistemas de assistência social e de saúde } \\
\text { dos funcionários públicos e dos trabalhadores do setor privado. }\end{array}$ \\
\hline $\begin{array}{l}\text { Novo estatuto de aposentação } \\
\text { Lei no } 52 / 2007 \\
\text { Lei no } 11 / 2008\end{array}$ & $\begin{array}{l}\text { Convergência dos direitos dos funcionários públicos com os dos trabalhadores } \\
\text { do setor privado. }\end{array}$ \\
\hline $\begin{array}{l}\text { Centralização da gestão de recursos e das } \\
\text { compras públicas } \\
\text { Decreto-Lei nํㅜ 37/2007 }\end{array}$ & $\begin{array}{l}\text { Centralização das compras públicas. } \\
\text { Centralização da gestão dos recursos humanos e financeiros. }\end{array}$ \\
\hline
\end{tabular}

Fonte: Elaborado pelo autor.

\section{A intervenção da troika e as medidas de reforma em época de austeridade}

De acordo com Cabral (2013), nas estatísticas disponíveis em 236 anos de história, Portugal registou apenas sete anos com uma balança comercial excedentária. O período mais recente em que ocorreu um superávit situou-se entre 1941-43, quando as exportações de volfrâmio de Portugal - utilizado na fabricação de munições e armas — para a Alemanha, o Reino Unido e os EUA levaram a três anos consecutivos de superávits comerciais. Ou seja, ao longo dos dois últimos séculos Portugal viveu quase permanentemente em défice. Por outro lado, recentemente, com a entrada em circulação do euro, à semelhança do que se passou com outros países periféricos, Portugal foi perdendo "competitividade" nas exportações, designadamente pelo fato de ter deixado de poder produzir e desvalorizar sua moeda. Ignorando essas variáveis e as consequências da austeridade já aplicada noutros países europeus de economia periférica, o memorando de entendimento com a troika (EC, IMF e ECB, 2011) veio exigir que um país que historicamente esteve em quase permanente balança comercial deficitária se transformasse numa economia modelar, o que dificilmente apresentaria quaisquer possibilidades reais de concretização no prazo de uma legislatura (Cabral, 2013).

As políticas de ajustamento que visavam a redução do défice estrutural das finanças públicas começaram em 2005, quando o Programa de Estabilidade e Crescimento 2005-09 foi lançado. Contudo, de acordo com Rato (2013a), até 2008, as políticas para redução do défice estrutural faziam parte de uma política mais abrangente, também orientada para o crescimento econômico, desenvolvimento tecnológico e até para a qualificação dos recursos humanos na administração.

A crise financeira internacional de 2008 contribuiu fortemente para que a meta de redução do défice estrutural não fosse alcançada. A partir de 2011, as diretivas constantes 
do Memorando de Entendimento com a troika (EC, IMF e ECB, 2011) e as opções políticas do XIX Governo Constitucional concorreram para criar medidas de austeridade visando dar resposta ao problema. Tendo em atenção o acordo celebrado entre o governo português e a troika, plasmado no Memorando de Entendimento, assistiu-se a uma perda de soberania do estado português na determinação das medidas de reforma da administração pública no país. Vergado a uma lógica de redução do défice, e consequentemente da despesa pública, o Memorando estabeleceu, antes de mais, metas concretas para a diminuição das despesas com pessoal no PIB português para o triênio 2012-14. Entre as metas propostas destacaram-se (EC, IMF e ECB, 2011):

- a preparação de um plano abrangente para promover a flexibilidade, a adaptabilidade e a mobilidade dos recursos humanos na administração pública, nomeadamente por meio da oferta de formação, nos casos em que for necessário, até ao fim de 2011;

- a limitação das admissões de pessoal na administração pública com vista a obter, entre 2012 e 2014, decréscimos anuais nos efetivos de 1\% por ano na administração central e de $2 \%$ nas administrações local e regional;

— o congelamento dos salários no setor público, em termos nominais, em 2012 e 2013, e a limitação das promoções;

— a redução do custo orçamental global com sistemas de saúde dos trabalhadores em funções públicas diminuindo a coparticipação da entidade empregadora (estado português) ajustando o âmbito dos benefícios de saúde, com poupanças que deveriam ascender a 100 milhões de euros só para o ano de 2012.

Tendo em vista o incremento da eficiência e da eficácia na APC, o Memorando (EC, IMF e ECB, 2011:14-15) estipula ainda uma série de outras medidas das quais nos permitimos destacar:

— a redução dos cargos dirigentes e dos serviços em, pelo menos, 15\% na administração central; a implementação de uma segunda fase do Prace até ao fim de 2011;

- a regulamentação de fundações, associações e outras entidades de caráter semelhante sob a alçada da administração central e local, e o encerramento das mesmas quando tal se justificasse até ao final de 2011.

Na prática, as metas que constam do memorando traduziram-se em medidas de reforma, muitas das quais foram aplicadas entre 2011 e 2013 sem que quaisquer estudos ou pareceres antecedessem e servissem de suporte à sua aplicação.

De acordo com o que havia sido determinado pelo Memorando de Entendimento (EC, IMF e ECB, 2011), o XIX Governo Constitucional assumiu, em seu Programa, a urgência de reduzir os custos do Estado e de procurar modelos mais eficientes de funcionamento, afirmando, nessa linha, a intenção expressa de eliminar as estruturas sobrepostas na estrutura do Estado, reduzindo o número de organismos e entidades, mantendo a qualidade na prestação do serviço público. Dessa forma, o Conselho de Ministros aprovou as linhas gerais do Plano de Redução e Melhoria da Administração Central (Premac), no âmbito do Compromisso Eficiência. Entre os objetivos do Plano, encontrava-se o da redução de pelo menos 15\% no total das estruturas orgânicas dependentes de cada ministério assim como nos cargos dirigentes. 
De acordo com Madureira, Asensio e Rodrigues (2013), a redução verificada, quer ao nível dos serviços, quer do número de dirigentes, ultrapassou o objetivo inicial. Contudo, ainda segundo os autores, a esmagadora maioria das competências existentes nos organismos extintos foi transferida para outras estruturas (algumas das quais já existentes, outras criadas para o efeito), não tendo havido propriamente uma extinção significativa de competências e atribuições da APC, mas antes um reenquadramento e uma redistribuição das mesmas por um número mais reduzido de organismos. Com efeito, a modalidade de reorganização predominante na administração central foi a fusão de estruturas. Ainda segundo o estudo de Madureira, Asensio e Rodrigues (2013), para já não foi efetuada nenhuma avaliação da eficiência, eficácia, melhorias qualitativas e reduções de custos resultantes do Premac, pelo que subsiste a dúvida sobre a efetividade da sua real utilidade.

No que concerne à profissionalização e à despolitização da gestão pública de topo, diversos autores nacionais se haviam já pronunciado sobre a necessidade da concretização das mesmas, de forma a assegurar o fim do spoil system e a reforçar a prossecução do interesse público (Ferraz, 2008; Madureira, 2013). É com base nessas premissas que o governo criou em 2011 a Comissão de Recrutamento e Seleção para a Administração Pública (CReSAP), que tem por responsabilidade proceder ao recrutamento e à seleção de candidatos para cargos de direção superior e avaliar o mérito dos candidatos a gestores públicos. Contudo, também nesse capítulo não existe para já qualquer processo de avaliação que permita clarificar se houve de fato uma democratização no acesso aos lugares cimeiros da administração.

Outra das medidas de reforma que apareceu como emblemática em 2013 foi o aumento do horário de trabalho na administração pública de 35 para as 40 horas. O principal argumento para a introdução da medida baseou-se na premissa de que essa seria uma forma de redução das horas de trabalho extraordinário e consequentemente traria uma poupança nos gastos com a remuneração dessas horas. Contudo, a medida foi aplicada sem que tivesse havido previamente um inventário de quais os organismos em que, de fato, havia um custo com horas de trabalho extraordinário. Ao aumento das horas trabalhadas não correspondeu um acréscimo de remuneração, o que implicou um decréscimo na remuneração na ordem dos 14\% (Rato, 2013b) assim como uma violação do contrato estabelecido entre as partes (Estado/funcionários), reduzindo uma já escassa motivação dos funcionários e estando em contraciclo com a média dos 28 países da União Europeia (Asensio et al., 2012). Para além disso, estudos recentes (Altman e Golden, 2007; Holman et al., 2008; Ngo et al., 2009; ILO, 2011) apontam, não só para a inexistência de uma relação direta entre o número de horas trabalhadas e a produtividade, mas também para o fato de a utilização de práticas de trabalho flexível tender a gerar um melhor clima organizacional, o que por sua vez tende a melhorar o desempenho das organizações.

A redução dos efetivos da APC foi também uma das metas do governo português durante a intervenção da troika no país. Essa redução fora já iniciada com o XVIII Governo Constitucional (liderado pelo partido socialista) com a introdução da regra do "um em dois", ou seja, a saída de dois trabalhadores na administração só permitia a entrada de um (Rato, 2013b). Em 2013, o XIX Governo Constitucional estabeleceu um Programa de Res- 
cisões por Mútuo Acordo para redução do número de trabalhadores menos qualificados, ao qual aderiram apenas 3.019 pessoas (Jornal de Notícias, 2013). Esse programa viria a estender-se aos técnicos superiores no início de 2014, tendo por objetivo aprofundar a diminuição do número de funcionários do Estado (Jornal de Notícias, 2013). Para melhor entendermos a evolução quantitativa que o emprego público tem vindo a sofrer em Portugal ao longo da última década é fundamental determo-nos nos dados oficiais apresentados para o efeito. De acordo com a DGAEP (2009), o total de efetivos da AP portuguesa (incluindo os níveis central, regional e local) era no fim do ano de 2005 de 747.880 funcionários. À data de 30 de junho de 2013, cifrava-se em 574.946 o número de funcionários (DGAEP, 2013b). Ou seja, ao longo dos últimos oito anos esse número não deixou de cair, tendo-se registado em média uma diminuição de $23,12 \%$ dos efetivos da administração pública portuguesa em seu conjunto.

A tentativa de redução do efetivo da função pública encontrou-se ainda plasmada no Diploma 177ㅇXXIII do Parlamento que tentou fazer aprovar a chamada Lei da Requalificação de acordo com a qual os funcionários, supostamente excedentários nos seus serviços, teriam 12 meses para se requalificarem para, a posteriori, serem recolocados noutro organismo público. Volvido esse intervalo de tempo, no caso de não ter havido uma nova colocação, os trabalhadores deveriam ser despedidos. Por não estar explícito no diploma como se desenrolaria todo o processo de requalificação e dada a "agressividade" das consequências eventuais da não recolocação, o Tribunal Constitucional chumbou a medida (Jornal "Público", 2013d). Só em novembro de 2013 a lei voltou a ser reapreciada, já com um alargamento do prazo em que os funcionários podem estar em período de requalificação e com a eliminação da possibilidade de despedimento (Jornal "Público", 2013b).

Se considerarmos como medida de reforma o corte nos salários dos funcionários públicos, de salientar que esse atingirá um peso que foi, de forma progressiva para todos os salários acima dos 600 euros, dos 2,5\% até aos 12\% dos vencimentos brutos (Jornal "Público", 2013c). Essa medida dá seguimento a outra, implementada pelo anterior governo, que já havia instituído cortes nos salários dos funcionários públicos, entre 3,5\% e 10\%. Contudo, a medida em causa só se aplicou, entre 2010 e 2013, para salários acima dos 1.500 euros (Jornal "Público", 2013e). Importa lembrar ainda que, durante o ano de 2012, os funcionários já se haviam visto privados dos seus subsídios de Natal e de férias, repostos a partir de 2013 por decisão do Tribunal Constitucional. Todos esses cortes acrescem a aumentos de impostos diretos significativos, aplicados a trabalhadores do setor público e privado, particularmente a partir do início de 2013 (no início do ano, o próprio ministro das Finanças referiu-se ao aumento de impostos como "enorme".), assim como ao congelamento dos salários e das promoções na função pública.

Também as contribuições obrigatórias dos funcionários para a Assistência na Doença dos Servidores do Estado (Adse) têm contribuído para uma perda de vencimento real. Com efeito, essa tem vindo a subir progressivamente de $1 \%$, atingindo os $2,5 \%$ a partir de janeiro de 2014 (Jornal "Económico", 2013), estando no presente momento em cima da mesa a possibilidade de essa contribuição vir a atingir os 3,5\% até 2016. 
Por fim, houve ainda uma tentativa do XIX Governo Constitucional de reduzir a despesa do erário público através da denominada “convergência das pensões”, que na prática significava um corte de $10 \%$ nas pensões de aposentação, reforma e invalidez de valor ilíquido mensal superior a 600 euros. Não obstante, uma vez mais o Tribunal Constitucional chumbou a supracitada medida, com o argumento de que ela violava os princípios da proteção e confiança que se afiguram como pilares fundamentais de um estado de direito.

\section{Conclusão}

Ao longo das últimas quatro décadas, passado que estava o período de conturbação pós-revolucionário, e apesar das idiossincrasias e especificidades decorrentes de uma história e tradição próprias, a reforma da administração pública portuguesa assemelhou-se em muito àquelas que foram acontecendo nos outros países ocidentais.

Durante a década de 1980, o movimento reformista fez um esforço no sentido da dignificação e formação dos dirigentes e dos funcionários públicos, da mudança de mentalidades e comportamentos no seio das estruturas, da flexibilização das cadeias de comando, da simplificação de regras e regulamentos e da passagem de um ambiente de trabalho dominado pelas regras para uma gestão flexível e motivada para o alcance de resultados.

Nos anos 1990 e no início do século XXI, a reforma administrativa em Portugal fica marcada pela coexistência, na prática, de três modelos de administração com distintos objetivos e filosofias organizacionais: o modelo estatutário, o modelo político e o modelo managerial, sendo o resultado dessa sobreposição a criação de um clima de contradição, em que se privilegiava o outsorcing e o downsizing, propostos pelo New Public Management, ao mesmo tempo que se preconizava a necessidade da participação dos funcionários nos processos de mudança.

Independentemente das incoerências observadas, esse período foi marcado pela introdução das privatizações, pela empresarialização da lógica administrativa, pelas tentativas de desburocratização e de proximidade e transparência na relação entre a administração e os cidadãos, pela convergência de regimes laborais e pela restruturação da administração pública central.

Ao longo da segunda metade da primeira década do novo século, criou-se em Portugal um novo estatuto para os funcionários públicos, com um novo sistema de posições remuneratórias em que a progressão estava sobretudo dependente dos resultados obtidos no sistema integrado de avaliação de desempenho na administração pública (Siadap). No essencial, procurou-se aproximar, tanto quanto possível, o regime de emprego público do existente no setor privado. De salientar ainda que, em 2006, o Prace iniciou a redução do número de estruturas e de cargos dirigentes.

A assinatura do Memorando de Entendimento entre o governo português e a troika levou a que durante os últimos três anos (2011 a 2013) as medidas de reforma da administração pública aplicadas em Portugal fossem essencialmente norteadas pelas metas constantes do documento. Na prática assistiu-se à institucionalização de um rol de medidas avulsas que almejou, antes de mais, um imediato corte dos custos da despesa pública. Até à data, não exis- 
tem estudos que avaliem as medidas de reforma/austeridade implementadas ao longo desse triênio que nos permitam aferir o impacto tido sobre o funcionamento da administração.

\section{Referências}

ALTMAN, Morris et al. The Economics of flexible work scheduling: theoretical advances and paradoxes. Research in the Sociology of Work, Oxford, v. 17, p. 313-342, 2007.

ARAÚJO, Joaquim F. A reforma administrativa em Portugal: em busca de um novo paradigma. Universidade do Minho, Núcleo de Estudos em Administração e Políticas Públicas, 2005. Disponível em <http://hdl.handle.net/1822/3274>. Acesso em: 21 jul. 2012.

ARAÚJO, Joaquim F. Reform and institutional persistence in Portuguese central administration. Tese (doutoramento em public management) — University of Exeter, Exeter, 1999.

ASENSIO, Maria et al. O modelo de organização e duração do tempo de trabalho na Administração Pública: análise comparada dos 27 Estados-membros da EU. Lisboa: DGAEP, 2012.

BILHIM, João. A avaliação de desempenho na administração pública. Revista de Administração e Políticas Públicas, v. 4, n. 1 e 2, p. 72-87, 2003.

BOVAIRD, Tony; LOFFLER, Elke. Evaluating the quality of public governance: indicators, models and methodologies. International Review of Administrative Sciences, v. 69, n. 3, p. 312-328, 2003.

CABRAL, Ricardo. Austerity measures in crisis countries - results and impact on mid-term development, forum with contributions of Monastiriotis, V., Hardiman, N., Regan, A., Goretti, C., Landi, L., Conde-Ruiz, J. I., Marín, C. and Cabral, R. Intereconomics - Review of European Economic Policy, v. 48, n. 1, p. 4-32, jan./fev. 2013.

CLARKE, John; NEWMAN, Janet. The managerial State: power, politics and ideology in the remarking of social welfare. Londres: Sage, 2000.

CÔRTE-REAL, Isabel et al. Les administrations en movement: les réformes de modernisation administrative dans quatre pays: Portugal, Pays Bas, Irlande et France. Maastricht: Eipa, 1999.

DECRETO-LEI 323/89 de 26 de setembro.

DENHARDT, Janet; DENHARDT, Robert. The new public service: serving nor steering. Nova York: M. E. Sharpe, 2003.

DGAEP. A década - Emprego público em números - 1996-2005. Lisboa: Direção-Geral da Administração e do Emprego Público, 2009.

DGAEP. Boletim Estatístico do Emprego Público, Lisboa, oㅜ 7, out. 2012.

DGAEP. Boletim Estatístico do Emprego Público, Lisboa, no 8, abr. 2013a.

DGAEP. Síntese Estatística de Emprego Público - 2º trimestre de 2013. Lisboa: Direção-Geral da Administração e do Emprego Público, 2013b. 
DIPLOMA 177ㅇXXIII.

EC, IMF e ECB. Portugal: Memorandum of Understanding on Specific Economic Policy Conditionality. 3 May 2011. (memorando de entendimento entre Portugal e a Troika, não publicado).

FERRAZ, David. A seleção de dirigentes públicos no contexto da evolução dos modelos de Estado e de administração. Contributo para a definição de uma política integrada. Dissertação (mestrado) ISCTE-Instituto Universitário de Lisboa, Lisboa, 2008.

GIAUQUE, David. New Public Management and organizational regulation: the liberal bureaucracy. International Review of Administrative Sciences, v. 69, n. 4, p. 567-592, 2003.

HOOD, Christopher. A public management for all seasons. Public Administration, v. 69, n. 1, p. 3-19, 1991.

HOLMAN, Corey et al. Labor productivity trends since 2000, by sector and industry. Monthly Labour Review, v. 131, n. 2, p. 64-82, 2008.

ILO. The effects of working time on productivity and firm performance: a research synthesis paper. Genéve, 2011.

IMF. Portugal rethinking the State: Selected expenditure reform options, document by Gerd Schwartz, Paulo Lopes, Carlos Mulas Granados, Emily Sinnott, Mauricio Soto, and Platon Tinios, 2013.

JORNAL DE NOTÍCIAS. Programa de rescisões para técnicos superiores do estado decorre entre 13 de janeiro e 11 de abril. 18 dez. 2013.

JORNAL "ECONÓMICO". Governo aprova atualizações dos valores das contribuições para a ADSE. 13 jun. 2013.

JORNAL "PÚBLICO". Novas regras da requalificação da função pública em vigor no domingo. 28 nov. 2013b.

JORNAL "PÚBLICO”. Salários acima de 1500 euros com cortes entre 3,5 e 10 por cento. 20 set. 2013e. JORNAL "PÚBLICO". Salários da função pública acima de 600 euros com cortes de 2,5\% a 12\%. 15 out. 2013c.

JORNAL "PÚBLICO". Tribunal Constitucional chumba por unanimidade convergência das pensões. 19 dez. 2013a.

JORNAL "PÚBLICO”. Tribunal Constitucional chumba requalificação da função pública. 29 ago. 2013d.

LANE, Jan-Erik. Public sector: concepts, models and approaches. Londres: Sage Publications, 1995.

LEI no 442/91 de 15 de novembro.

LEI no 13/97 de 23 de maio.

LEI no 2/2004 de 15 de janeiro.

LEI no 51/2005 de 30 de agosto. 
MADDOCK, Su. Making modernization work: new narratives, change strategies and people management in the public sector. The International Journal of Public Sector Management, v. 15, n. 1, p. 13-43, 2002.

MADUREIRA, César. A formação comportamental no contexto da reforma da administração pública portuguesa. Oeiras: Edições INA, 2004.

MADUREIRA, César. Profissionalização e avaliação dos dirigentes de topo na administração pública: o caso de Portugal. In: MADUREIRA, César; ASENSIO, Maria (Org.). Handbook de administração pública. Lisboa: Editora INA, 2013. p. 159-172.

MADUREIRA, César; ASENSIO, Maria; RODRIGUES, Miguel. Análise da evolução das estruturas da administração pública central portuguesa decorrente do Prace e do Premac. Lisboa: DGAEP, 2013.

MADUREIRA, César; FERRAZ, David. The need of a XXI century governance paradigm for public administration - the specific case of Portugal. Public Policy and Administration-Viesoji Politika ir Administravimas, n. 31, p. 35-48, 2010.

MADUREIRA, César; RODRIGUES, Miguel. A administração pública do século XXI: aprendizagem organizacional, mudança comportamental e reforma administrativa. Comportamento Organizacional e Gestão, v. 12, n. 2, p. 153-172, 2006.

MADUREIRA, César et al. A reforma da administração pública em Portugal no pós-25 de Abril e a implementação do Premac: avaliação intercalar do Plano de Redução e Melhoria da Administração Central do Estado em 15 de setembro de 2012. Direção Geral de Administração e do Emprego Público. Lisboa: DGAEP, 2012.

NGO, Hang-Y.; FOLEY, Sharon; LOI, Raymond. Family friendly work practices, organizational climate, and firm performance: a study of multinational corporations in Hong Kong. Journal of Organizational Behavior, v. 30, p. 665-680, 2009.

NUTLEY, Sandra; BOAZ, A. Evidence-based policy and practice. In: BOVAIRD, Tony; LOFFLER, Elke (Ed.). Public management and governance. Londres: Routledge, 2003.

OECD. Government at a glance. Paris: Oecd, 2013.

OECD. Managing administrative reform: a case study of Portugal (1976-1994). Public Management Occasional Papers, Paris: Puma, 1995.

PETERS, B. Guy. The future of governing: four emerging models. Kansas: University Press of Kansas, 1996.

PETERS, B. Guy; SAVOIE, Donald J. Managing Incoherence: The coordination and empowerment conumdrum. Public Administration Review, v. 56, n. 3, p. 281-290, 1996.

POLLITT, Christoph; BOUCKAERT, Geert. Public management reform: a comparative analysis. Oxford: Oxford University Press, 2000.

RATO, Helena. Análise crítica do Capítulo III — Salários e Emprego, do Relatório do IMF: Portugal rethinking the State — selected expenditure reform options. Lisboa: DGAEP, 2012. 
RATO, Helena. Contrarreforma da administração pública pela mão da troika. Seara Nova, n. 1725, p. 14-19, 2013b.

RATO, Helena. Portugal: structural reforms interrupted by austerity. In: VAUGHAN-WHITEHEAD, Daniel (Ed.). Public sector shock: the impact of policy retrenchment in Europe. Geneva: ILO, 2013a.

RESOLUÇÃO de Conselho de Ministros no 124/2005.

ROCHA, José A. O. Gestão pública e modernização administrativa. Oeiras: INA, 2009.

ROCHA, José A. O. La fin de l'État administratif au Portugal. Revue Française d'Administration Publique, n. 86, p. 219-229, 1998.

ROCHA, José A. O.; ARAÚJO, Joaquim F. Administrative reform in Portugal: prospects and dilemmas. In: EUROPEAN GROUP OF PUBLIC ADMINISTRATION (EGPA) ANNUAL CONFERENCE, 2006, Milão. Disponível em: <http://hdl.handle.net/1822/5753>. Acesso em: 20 jun. 2009.

UN, What is good governance? 2008. Disponível em <www.unescap.org/pdd/prs/ProjectActivities/ Ongoing/gg/governance.asp>. Acesso em: 20 jun. 2009.

WRIGHT, Vincent. Redefiniendo el Estado: las implicaciones para la administración pública. Gestion y Analisis de Políticas Públicas, n. 7/8, p. 27-44, 1997.

César Madureira é doutor em gestão e professor auxiliar na Universidade Lusíada de Lisboa. Exerce ainda as atividades de investigador principal na Direção-Geral de Administração e Emprego Público (DGAEP) e de professor convidado no Mestrado de Administração Pública, no Instituto Superior de Ciências do Trabalho e da Empresa - Instituto Universitário de Lisboa (ISCTE-IUL). E-mail: cesar.madureira@ dgaep.gov.pt. 